\title{
Bilateral Brenner tumor of ovary with associated unilateral mucinous cystadenoma: a case report
}

\author{
Natasha Mittal ${ }^{1 *}$, Bhaskar Das $^{2}$, Seema Manuja $^{3}$, Renu Gupta ${ }^{3}$
}

\begin{abstract}
${ }^{1}$ Department of Pathology, ${ }^{2}$ Department of Microbiology, ${ }^{3}$ Department of Obstetrics and Gynecology, Sarvodaya Hospital and Research Centre, Faridabad, Haryana, India
\end{abstract}

Received: 24 February 2019

Accepted: 08 April 2019

\section{*Correspondence:}

Dr. Natasha Mittal,

E-mail: dr.natashamittal@yahoo.com

Copyright: (c) the author(s), publisher and licensee Medip Academy. This is an open-access article distributed under the terms of the Creative Commons Attribution Non-Commercial License, which permits unrestricted non-commercial use, distribution, and reproduction in any medium, provided the original work is properly cited.

\begin{abstract}
Brenner tumors are rare ovarian tumors, which are a subgroup of transitional cell tumors of ovary. Most of these tumors are benign presenting as incidental unilateral masses in postmenopausal age group. Only 5-7\% cases are bilateral. These tumors are mostly small, solid and asymptomatic, seen commonly in association with mucinous cystadenomas of ovary. In such cases they may attain a massive size. Specific diagnosis of Brenner tumor is difficult using imaging studies and can be definitely diagnosed only on pathological examination. Surgical removal is usually curative for benign tumors. We present a rare case of bilateral Brenner tumor of ovary with associated unilateral mucinous cystadenoma in which bilateral Brenner tumor was a rare incidental finding on pathological examination.
\end{abstract}

Keywords: Brenner tumor, Mucinous cystadenoma, Ovarian tumor

\section{INTRODUCTION}

Ovarian tumors account for around $30 \%$ of female genital cancers. Usually ovarian tumors remain asymptomatic for a long period of time and are diagnosed only after attaining a larger size. Brenner tumors are a subgroup of transitional cell tumors of the ovary. ${ }^{1}$ They are very rare types of ovarian neoplasm accounting for $2-3 \%$ of all ovarian neoplasms. Most of them are diagnosed as incidental intra-operative or pathological finding. ${ }^{2}$ Mostly they are benign and incidence of malignancy has been found to be $2 \%$ of all cases and less than $5 \%$ cases are proliferating or borderline tumors. ${ }^{3}$ These tumors are epithelial ovarian tumors formed by cells that resembles internal lining of urinary bladder and presumed to be derived from surface ovarian epithelium that undergoes urothelial metaplasia. ${ }^{4}$ The average age of presentation is 50 years with $71 \%$ of the patients being more than 40 years. ${ }^{3}$ This tumor mostly occurs in the postmenopausal women. They are generally unilateral, only $5-7 \%$ of cases are bilateral. ${ }^{5}$ These tumors are mostly small, solid masses of up to $2 \mathrm{~cm}$ in size. These tumors may attain massive size when they occur in association with mucinous or serous cystadenomas which is seen in about $20 \%$ of cases. $^{6}$ Cystadenomas may arise from the epithelium of Brenner tumor. At times direct transition from Brenner epithelium to mucinous epithelium can be seen microscopically. Very occasionally the coexisting tumor is struma ovarii or a teratoma. ${ }^{7}$

\section{CASE REPORT}

A 55 year old postmenopausal patient presented in the Gynaecology department of our hospital with complaint of pain and heaviness in the lower abdomen. There was past history of lipoma in left inguinal region and an endocervical polyp both of which were surgically 
excised. Ultrasound of abdomen and pelvis revealed a left sided adenexal mass measuring $5 \times 3 \times 2 \mathrm{~cm}$ with both solid and cystic components suggestive of an ovarian tumor. There was no history of abnormal uterine bleeding. No past history of diabetes or hypertension was there. The patient was positive for Hepatitis B surface antigen. Total abdominal hysterectomy with bilateral salpingooophorectomy with pre-operative imprint cytology was planned for this patient as there was suspicion of malignant ovarian tumor.

Intra-operative imprint cytology from solid areas of the left ovarian cyst was done. Imprint smears showed sheets of polygonal epithelial cells with round to oval nuclei. There was no evidence of nuclear atypia or pleomorphism. It was reported as benign ovarian tumor on imprint cytology.

The post-operative specimen received was of left ovary with cyst along with uterus, cervix, bilateral fallopian tubes and right ovary. On gross examination right ovary measured $2.5 \times 2 \times 1 \mathrm{~cm}$. Cut section was solid with presence of creamish yellow area measuring $8 \times 8 \mathrm{~mm}$. Left ovarian tumor showed presence of multiple cysts filled with mucin. Intramural solid creamish brown nodules were seen. No papillae etc were seen. Gross examination of uterus, cervix and fallopian tubes were unremarkable.

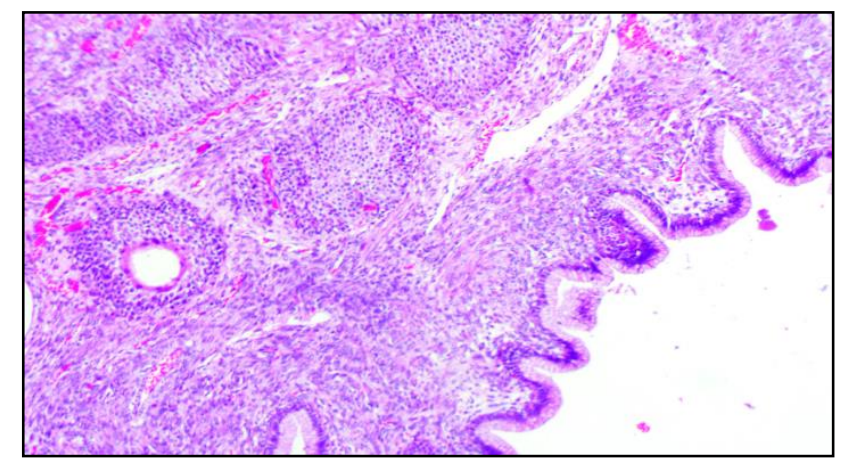

Figure 1: Micrograph showing mucinous lining epithelium of ovary with presence of multiple nests of transitional cells with surrounding fibrous stroma $(\mathbf{H}$ and E; low power).

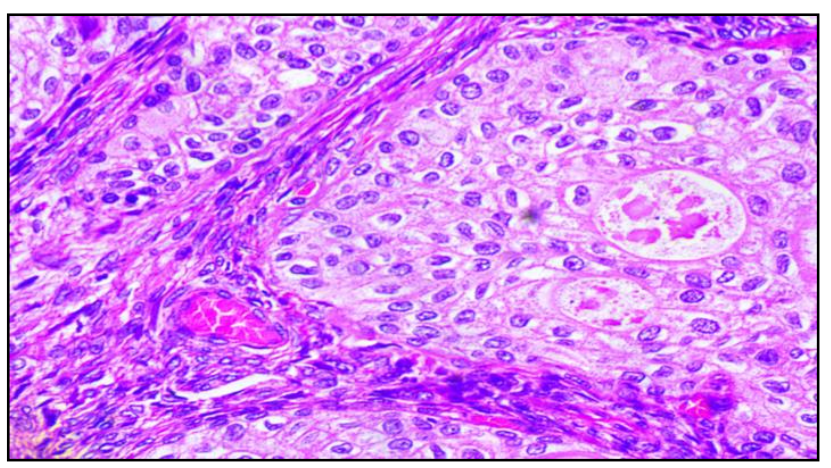

Figure 2: Micrograph showing coffee bean nuclei with central longitudinal grooves ( $\mathrm{H}$ and $\mathrm{E}$; high power).

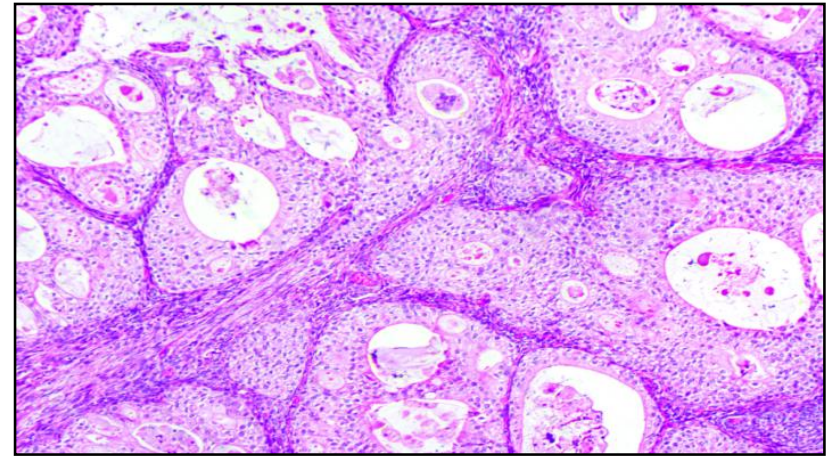

Figure 3: Micrograph showing multiple transitional epithelial cell nests ( $H$ and $E$, low power).

Microscopic examination of left ovarian tumor showed multiple cysts lined by mucinous epithelium. Few solid and cystic nests of urothelium like cells surrounded by dense fibrous stroma were seen (Figure 1). The epithelial cells were well defined, uniform, and polygonal with pale cytoplasm, prominent single nucleolus and grooved nuclei giving a coffee bean appearance. No evidence of nuclear atypia or mitosis was seen (Figure 2). Sections from right ovary showed solid and cystic nests of urothelium like cells surrounded by fibrous stroma (Figure 3). The above microscopic findings were consistent with bilateral benign Brenner tumor with associated benign mucinous cystadenoma in left ovary.

The post operative period was uneventful and the patient was discharged with advice of regular follow-up.

\section{DISCUSSION}

Brenner tumor of ovary is a solid ovarian tumor that is generally asymptomatic. It is usually an incidental pathological finding. Among symptomatic patients common symptoms include vaginal bleeding, a palpable pelvic mass and pelvic pain. ${ }^{6}$ Rarely tumors can produce estrogen and this may be a cause of vaginal bleeding. ${ }^{8}$ In our case the patient presented with symptoms of pain and heaviness in the lower abdomen due to left sided adenexal mass which was benign Brenner tumor associated with mucinous cystadenoma. The right sided Brenner tumor was an incidental finding.

Brenner tumors have a nonspecific appearance on USG and Computed Tomography. They are difficult to diagnose with imaging studies as benign Brenner tumor appears similar to those of other solid ovarian masses such as fibroma, fibrothecoma and pedunculated leiomyoma. ${ }^{9}$ Brenner tumors have a slow rate of growth and rarely they are associated with ascites. It is not unusual for Brenner tumor to coexist with other neoplasms. Most frequently they are associated with cystadenomas. ${ }^{10}$ On gross examination Brenner tumors are solid, well circumscribed, pale yellow to grey white in colour with a solid or fibromatous cut surface. The tumors vary in size from $1 \mathrm{~cm}$ to $30 \mathrm{~cm}^{3}$ Tumor size may 
correlate with tumor type. Benign tumors are usually smaller than $4.5 \mathrm{~cm}$ at presentation, where as malignant tumors tend to be larger than $5 \mathrm{~cm} .{ }^{8}$ Microscopically, they show presence of abundant dense fibrous stroma with epithelial nests of transitional cells resembling urothelium. In borderline or malignant tumors the fibrous component is less prominent. Most Brenner tumors are candidates for surgical resection which is usually curative in most cases. ${ }^{5}$

Because of its rarity and disputed histogenesis Brenner tumor has always remained an enigmatic entity among pathologists. This case has been presented because of the rare concurrence of bilateral Brenner tumor and its association with mucinous cyatadenoma on one side.

\section{ACKNOWLEDGMENTS}

Author would like to thank her husband and father for their continuous support and encouraging for this study.

Funding: No funding sources

Conflict of interest: None declared

Ethical approval: Not required

\section{REFERENCES}

1. Tiwari N, Gandhi H. Benign Brenner tumor of ovary- A rare case report. IAIM. 2018;5(10):153-6.

2. Giriyan SS, Barnawal AA. Mucinous cystadenoma of ovary with benign brenner component: a case report. J Med Dent Sci Res. 2015;2(8):7-10.

3. Jodha BS, Garg R. Brenner tumor of ovary: an incidental finding: a case report. Int $\mathrm{J}$ Reprod Contracept Obstet Gynecol. 2017;6(3):1132-5.
4. Chen VW, Ruiz B, Killeen JL, Cote TR, Wu XC, Correa CN. Pathology and classification of ovarian tumors. Cancer. 2003;97(10 Suppl):2631-42.

5. Katke RD, Acharya S. Huge Brenner's tumour of ovary $(6.2 \mathrm{~kg})$ in a postmenopausal female - a rare case report and review of literature. J Gynecol Women's Health. 2017;Doi:10.19080/JGWH.2017.02.555583.

6. Pradhan P, Mohanty L, Pradhan D, Pujari S, Kar A. Benign brenner tumor of ovary with mucinous cystadenoma: A case report. Asian J Pharm Hea Sci. 2017;7(1):1643-6.

7. Dierickx I, Valentin L, Holsbeke CV, Jacomen G, Lissoni AA, Licameli A, et al. Imaging in gynecological disease (7): clinical and ultrasound features of Brenner tumors of the ovary. Ultrasound Obstet Gynecol. 2012;40:706-13.

8. Vukmirovic F, Vukmirovic IT, Vukmirovic M. Clinicopathological features of ovarian Brenner tumors in Montenegro. Cent Eur J Med. 2013;8(2):146-8.

9. Borah T, Mahanta RK, Bora BD, Saikia S. Brenner tumor of ovary: An incidental finding. J Mid-life Health. 2011;2:40-1.

10. Wasim S, Ahmad S. Right serous cystadenoma with left Brenner tumour in a post-menopausal female: a rare case of bilateral ovarian tumour. research and reviews: J Med Health Sci. 2014;3(4):59-62.

Cite this article as: Mittal N, Das B, Manuja S, Gupta R. Bilateral Brenner tumor of ovary with associated unilateral mucinous cystadenoma: a case report. Int J Reprod Contracept Obstet Gynecol 2019;8:2122-4. 